\title{
Energy intake and basal metabolic rate during maintenance chemotherapy
}

\author{
S A Bond, A M Han, S A Wootton, J A Kohler
}

\begin{abstract}
Energy intakes and basal metabolic rates were determined in 26 children receiving chemotherapy in remission from acute lymphoblastic leukaemia or solid tumours and 26 healthy controls matched for age and sex. Body weight and height on the two groups were comparable, although one patient was stunted (height for age) and three others wasted (weight for height). Energy intake in the patients at $7705 \mathrm{~kJ} /$ day (1842 kcal) and controls at $7773 \mathrm{~kJ} /$ day (1866 kcal)) and basal metabolic rate $(B M R)$ in the patients at $4873 \mathrm{~kJ} /$ day (1172 kcal) and controls $4987 \mathrm{~kJ} /$ day (1196 kcal) for the two groups were not significantly different. Although the energy intake:BMR ratio for both groups was $1 \cdot 59$, the range of values for the patient group was large (0.962.73) and appeared to be greater than that observed in the control group (1.23-2.46). These results demonstrated that during this period of chemotherapy there was no evidence of raised energy expenditure at rest or reduced energy intake in the patient group. No indication of undernutrition in the patients as a group was evident, although some individuals might require further clinical nutritional assessment.
\end{abstract}

Malnutrition is one of the major problems for children with cancer. ${ }^{1}$ Previous studies have shown that at diagnosis these patients are adequately nourished, suggesting that the cause of the malnutrition is predominantly iatrogenic. ${ }^{2}$ Though the link between nutritional status and clinical outcome remains incompletely defined, impaired immune function associated with the therapeutic management in combination with malnutrition, either additively or synergistically, may increase the susceptibility of the child to infection. ${ }^{3}$ This in turn may influence clinical outcome.

In the long term poor nutrition will also limit growth and development. Growth deficits have been recorded in a large group with a diagnosis of acute lymphoblastic leukaemia but it was unclear whether the deficit was attributable to the disease process itself, infection, or the therapeutic management of the patient. ${ }^{4}$

Attention has been principally directed towards studying the changes in energy intake and expenditure during the initial period of intensive treatment after diagnosis. ${ }^{5-7}$ Energy requirements may be raised as a result of cachectic side effects of treatment or infection. The limited number of published studies in children with recently diagnosed cancer have suggested that energy expenditure at rest may indeed be greater than predicted..$^{5-7}$ However, in two studies this appeared to be normalised within seven days of initial treatment. ${ }^{56}$ In the study conducted by Merritt and colleagues basal metabolic rate (BMR) was raised over a period of 30 days. $^{7}$ Although all these studies appear to indicate some degree of raised metabolism at diagnosis of cancer and during the first month of treatment, energy requirements during the longer period of maintenance chemotherapy that follows remain unknown.

The purpose of this study was to examine the effect of maintenance chemotherapy alone on the energy intake and BMR of patients without active disease. Measurements of energy intake and BMR were carried out in a group of patients receiving continuous chemotherapy, after the attainment of remission from acute lymphoblastic leukaemia or solid tumours. Their results were compared with those from normal healthy children matched for age and gender.

\section{Subjects and methods}

PATIENTS

Twenty six children (aged 5 to 16 years) receiving chemotherapy took part in the study. Sixteen patients with a diagnosis of acute lymphoblastic leukaemia were on Medical Research Council UK acute lymphoblastic leukaemia (UKALL) trials (three girls, 13 boys). Their diagnosis was made a minimum of six months before this study. Measurements of energy intake and BMR were made in the week before their monthly vincristine and prednisolone block.

The remaining 10 patients (seven girls, three boys) included one with chronic granulocytic leukaemia and nine with various solid tumours. They were all on UK Children Cancer Study Group (UKCCSG) trials or related studies. Before participating in this study each patient had received a minimum of three courses of chemotherapy, in addition to initial diagnostic or therapeutic surgery. Energy balance was assessed in the week before a block of chemotherapy. All patients were clinically well and afebrile throughout the study period.

\section{CONTROLS}

Local schools,were approached for control subjects. Both parents and head teachers gave their consent for the children who volunteered to participate in this study. They were all free from illness at the time the energy balance measurements were made. Ethical approval for the study was granted by the Southampton and South West Hampshire Health Authority.
Correspondence to: Dr Wootton.

Accepted 4 November 1991 
METHODS

Weighed dietary intake was recorded for a period of seven days in the standard manner described by Marr, using digital electronic scales (Hanson). ${ }^{8}$ The children and their families were instructed in the use of the scales and how to record their food and drink consumption in a notebook provided. The dietary record was checked during a follow up interview with the dietitian (SAB). These were then coded according to the McCance and Widdowson food tables, ${ }^{9}$ with additional data from the supplements to the food tables ${ }^{10-12}$ and manufacturers' information. Using a computerised database (Microdiet), analysis was carried out to determine the estimated metabolisable energy intake over the seven day period. Energy intakes were expressed in absolute units, corrected for differences in fat free mass, and in relation to that recommended by the Department of Health and Social Security. ${ }^{13}$

In this study, energy expenditure at rest or BMR was defined as the minimum energy expenditure for maintaining essential bodily functions under standardised resting conditions, 12-18 hours' postprandial, in a neutral thermal environment. ${ }^{14}$ All measurements were performed between 0730 and 1030 after an overnight fast. BMR was determined by indirect calorimetry using an open circuit ventilated hood system. Oxygen consumption and respiratory exchange ratio were measured to calculate BMR. ${ }^{15}$ During the measurement the subjects lay supine on a bed listening to selected music or story tapes. Room temperature was maintained at $22-24^{\circ} \mathrm{C}$. The measurements were conducted for a minimum period of 30 minutes after a stable energy expenditure was achieved.

BMR was expressed in $\mathrm{kJ} / \mathrm{day}$, corrected for difference in fat free mass, and as a percentage of that predicted on the basis of age, gender, weight, and height. ${ }^{16}$

Height was determined using a Holtain stadiometer. Weight was determined by standing balance scales. Standard deviation (SD) scores were determined for height. Nutritional status was described by determining weight for height as a percentage, and height for age as a percentage, using Tanner and Whitehouse centile charts. ${ }^{17}$

Fat free mass was determined from skinfold thickness (biceps, triceps, subscapular, and suprailiac) measured by Holtain calipers. Both the equations of Brook $^{18}$ and Durnin and Rahaman ${ }^{19}$ were used to estimate body density because of the wide range of ages within the groups. Siri's equation was used to estimate fat mass. ${ }^{20}$ The significance of differences between groups was assessed from the unpaired Student's $t$ test.

\section{Results}

The characteristics of patients and controls are shown in table 1 . The healthy controls had a mean height for age of $101 \%$ (range $94-111 \%$ ) and a mean weight for height of $102 \%$ (range $82-132 \%)$. Their mean SD score for height was -0.09 with a range of -1.6 to 1.67 . Thus all the controls were within +2 SD scores of the median for height. These values would suggest that the control group were representative of the normal healthy population of children.

The mean values for body size and composition of the patients were similar to those of their controls. However, when the range of values for the patients' height for age (52-166\%) and weight for height $(66-125 \%)$ were considered, four patients appeared to be in the poorly nourished range according to the classification of Waterlow et al. ${ }^{2122}$ One patient (with acute lymphoblastic leukaemia) was less than $90 \%$ of height for age, or stunted, and three patients (with solid tumours) were less than $80 \%$ of weight for height, or wasted. The group with acute lymphoblastic leukaemia tended to be relatively shorter but exhibited a greater weight for their height than the group with solid tumours.

The mean BMR of the two groups whether expressed as $\mathrm{kJ} /$ day, or in $\mathrm{kJ} / \mathrm{kg}$ of fat free mass/day, were very similar (see table 2 ). When

Table 1 Age and anthropometric variables of healthy controls and patients receiving chemotherapy. Values are mean (SEM)

\begin{tabular}{lllll}
\hline & Controls & $\begin{array}{l}\text { Acute lymphoblastic } \\
\text { leukaemia and } \\
\text { solid tumour }\end{array}$ & $\begin{array}{l}\text { Acute lymphoblastic } \\
\text { leukaemia }\end{array}$ & $\begin{array}{l}\text { Solid } \\
\text { tumour }\end{array}$ \\
\hline Age (years) & $10 \cdot 0(0 \cdot 6)$ & $10 \cdot 1(0 \cdot 6)$ & $10 \cdot 1(1 \cdot 0)$ & $10 \cdot 0(1 \cdot 0)$ \\
Weight (kg) & $33 \cdot 1(2 \cdot 4)$ & $32 \cdot 4(2 \cdot 3)$ & $31 \cdot 6(2 \cdot 4)$ & $33 \cdot 7(4 \cdot 5)$ \\
Height (cm) & $136 \cdot 4(3 \cdot 4)$ & $138 \cdot 3(3 \cdot 7)$ & $135 \cdot 5(4 \cdot 3)$ & $142 \cdot 9(6 \cdot 7)$ \\
SD score & $-0 \cdot 09(0 \cdot 16)$ & $0 \cdot 14(0 \cdot 27)$ & $100(3)^{*}$ & $0 \cdot 33)$ \\
Weight for height (\%) & $102(2)$ & $94(3)$ & $100(6)$ & $85(3)^{*}$ \\
Height for age (\%) & $101(1)$ & $101(1)$ & $25 \cdot 4(1 \cdot 9)$ & $104(2)$ \\
Fat free mass & $27 \cdot 2(1 \cdot 9)$ & $26 \cdot 3(1 \cdot 7)$ & $27 \cdot 6(3 \cdot 4)$ \\
\hline
\end{tabular}

${ }^{*}$ Solid tumour significantly different from acute lymphoblastic leukaemia at $\mathrm{p}<0 \cdot 01$.

Table 2 Energy intake and BMR of healthy controls and patients receiving chemotherapy. Values are mean (SEM)

\begin{tabular}{llllc}
\hline & Controls & $\begin{array}{l}\text { Acute lymphoblastic } \\
\text { leukaemia and } \\
\text { solid tumour }\end{array}$ & $\begin{array}{l}\text { Acute lymphoblastic } \\
\text { leukaemia }\end{array}$ & $\begin{array}{l}\text { Solid } \\
\text { tumour }\end{array}$ \\
\hline BMR (kJ/day) & & $4873(207)$ & $4852(254)$ & $4907(372)$ \\
BMR (kcal/day) & $4987(183)$ & $1166(50)$ & $1161(61)$ & $1174(89)$ \\
BMR/kg fat free mass (kJ/kg/day) & $1193(44)$ & $194(7)$ & $198(7)$ & $189(13)$ \\
\% Predicted as \% of predicted BMR & $101(3)$ & $98(2)$ & $97(2)$ & $100(3)$ \\
Energy intake (kJ/day) & $7773(261)$ & $7705(459)$ & $7617(584)$ & $7846(782)$ \\
Energy intake (kcal/day) & $1860(62)$ & $1843(110)$ & $1822(140)$ & $1877(187)$ \\
Energy intake/kg fat free mass (kJ/kg/day) & $308(14)$ & $304(14)$ & $310(19)$ & $296(21)$ \\
Energy intake as \% of RDA & $87(10)$ & $85(4)$ & $83(6)$ & $89(7)$ \\
\hline
\end{tabular}




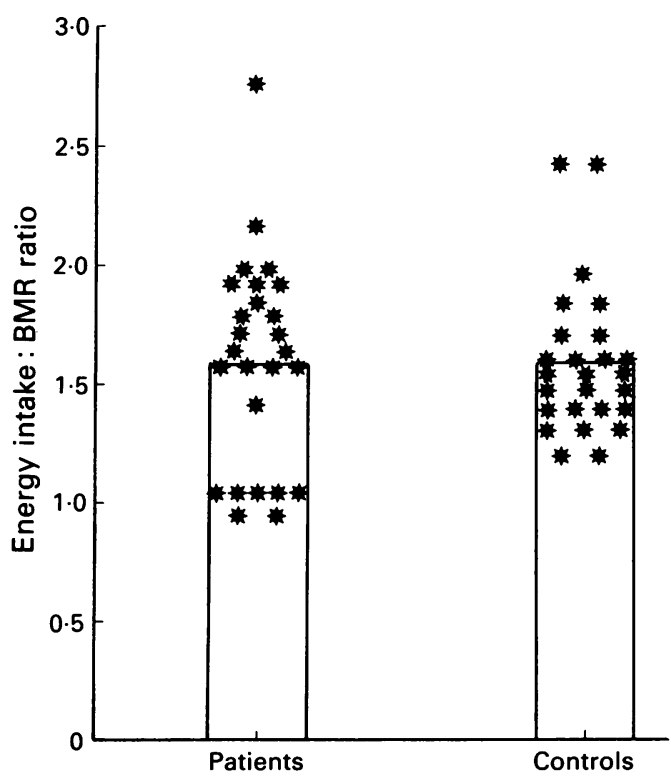

Individual energy intake: $B M R$ ratio for 26 healthy controls and 26 patients receiving chemotherapy (both acute lymphoblastic leukaemia and solid tumours). Bar indicates mean value for group.

the measured BMR was expressed as a percentage of the BMR predicted for age, gender, height, and weight, ${ }^{16}$ there was no significant difference between the two groups. There were no apparent differences in BMR between the two treatment groups.

The range of values for energy intake was larger in the patient group: 4.4-13.2 MJ/day (1053 kcal-3158 kcal) than the control group: 5.5-10.9 MJ/day (1316-2608 kcal). However, the mean energy intake values were very similar whether expressed as $\mathrm{kJ} /$ day or $\mathrm{kJ} / \mathrm{kg}$ of fat free mass/day (see table 2). When the mean energy intake of the two groups were compared as a percentage of the recommended daily amount for energy, ${ }^{13}$ the chemotherapy group value $(85 \%)$ was not significantly different from that of the control group $(87 \%)$. There were no apparent differences in energy intake between the two treatment groups.

When the energy intake is expressed as a ratio of the BMR the mean values for the two groups were exactly the same, $1 \cdot 59$. The range of values does vary considerably, especially for the patient group: patients, $0.96-2.73$ and controls, 1.23-2.46 (see figure). There were no apparent differences in energy intake:BMR ratio between the two treatment groups.

\section{Discussion}

Parents of children receiving cytotoxic drugs often express concern that their child may not be eating adequately to satisfy their body's requirements for energy and nutrients. Anorexia and weight loss are prevalent in cancer patients, and those children who have been receiving treatment for long periods of time are more likely to be malnourished. ${ }^{23}$ Furthermore several studies which followed up children in long term remission from cancer demonstrated a tendency toward poor growth. ${ }^{44-26} \mathrm{~A}$ limitation in growth has to relate to an imbalance between energy intake and energy expenditure and must include consideration of three factors: poor dietary intake, increased faecal losses, and the nature and magnitude of metabolic demand. Deficiencies of specific micronutrients that may also limit growth once energy needs are satisfied should not be overlooked.

Two studies have measured energy expenditure at rest in children with cancer. Kien and Camitta report a limited series of observations in eight children with newly diagnosed acute lymphocytic leukaemia. ${ }^{5}$ BMR was measured by indirect calorimetry for a five minute period during which time some of the children slept. The results were expressed as a percentage of published values for normal children and revealed that the mean increase in BMR was $50 \%$ (range 16-166\%) above normal. This study is frequently cited as evidence of a raised metabolic demand in children with cancer. It should be noted that apart from potential errors associated with such a brief period of measurement, no attempts were made to compare these results with the BMR determined in a control group. It is also not possible to determine whether these measurements were made before or after treatment was initiated.

In a subsequent study by Stallings et al greater attention was paid to technical detail and measurements of BMR were made in nine children with newly diagnosed acute lymphoblastic leukaemia before and during the first two weeks of chemotherapy. ${ }^{6}$ Energy expenditure at rest was determined in the patients who were subdivided into two groups with differing tumour burden. They found that only the three patients with a high white cell count at diagnosis exhibited a BMR that was $13-45 \%$ greater than that predicted from age, sex, and size. The remaining six patients with low tumour burden exhibited BMR values comparable with that predicted from age, sex, and size. The raised BMR of the high tumour burden group rapidly returned to normal with treatment. While chemotherapy treatment per se did not appear to raise $B M R$, changes in substrate utilisation were observed that appeared to be more persistent. They noted that as most chemotherapy programmes for children with acute lymphoblastic leukaemia last up to three years, longitudinal follow up of intermediary metabolism is important to determine whether there is a profound and permanent effect on metabolism, growth, and development.

In this present study energy intakes and BMRs were determined in children receiving ongoing chemotherapy while otherwise well and having no evidence of active disease. Both patients and healthy controls appeared to consume equivalent amounts of energy with their mean values between $13-15 \%$ less than their recommended daily amount for energy. Both groups exhibited values for BMR that were comparable, whether expressed in standard units, per $\mathrm{kg}$ of fat free mass, or as a percentage of that predicted from age, sex, height, and weight.

The mean ratio of energy intake to $B M R$ (BMR factor) was the same for both groups, 1.59. There is very little published information on energy intake:BMR ratios in children of this 
age group against which our results may be compared. This value is slightly lower than the desirable energy allowance for populations expressed as a ratio of BMR estimated from patterns of physical activity for this age group (boys $1 \cdot 76$, girls $1 \cdot 65$ ). ${ }^{27}$ The range of BMR factors of the patients was large $(0 \cdot 96-2 \cdot 73)$ and appeared to be greater than that reported for the control group $(1 \cdot 23-2 \cdot 46$; see figure).

Seven of the children receiving chemotherapy reported energy intakes that were less than or only slightly greater than their BMR values. These patients were not the ones who fell into the category of being stunted or wasted. Those patients already showing signs of poor growth may have experienced energy deprivation in the past and their metabolism adapted to the reduced intake. There would be no method of measuring whether this was during early childhood, at the time of the initial disease, or during previous treatment.

Though this may be interpreted as evidence that the food intake of these children was insufficient, it is important to recognise that this may also reflect the under-reporting of food intake. ${ }^{28}$ Considerable efforts were taken in this study to limit the possibility of inaccurate reporting of food intake. In addition the problem of undereating during the period of measurement should not be ruled out. ${ }^{29}$ There was no evidence of energy imbalance, as indicated by measurements of weight, between the start and end of the diary recording. It was not possible to make measurements of habitual physical activity during this study.

This study represents the first occasion in which energy intakes and basal metabolic rates have been determined beyond induction chemotherapy. We found that in the week before chemotherapy the dietary intake of energy and the expenditure of energy at rest of a group of patients receiving chemotherapy gave little evidence to suggest that undernutrition was a problem for these patients. However, the sample size was relatively small, the group fairly heterogeneous and possibly not representative of their respective patient populations. For example the patients with acute lymphoblastic leukaemia were older than a typical patient population. If there is a long term energy deficit leading to poor growth in some children with acute lymphoblastic leukaemia, further studies need to investigate these components of energy balance during other stages of the cycle of treatment and with a younger homogeneous patient group.

We thank the children and their parents whose cooperation was essential for the completion of this study. JAK is supported by the Leukaemia Research Fund. The support of the Wessex Medical Trust is gratefully acknowledged.
1 van Eys J. Malnutrition in children with cancer. Cancer 1979;43:2030-5

2 Smith DE, Stevens MCG, Booth IW. Malnutrition in children with malignant solid tumours. Fournal of Human Nutrition and Dietetics 1990;3:303-8.

3 van Eys J. Nutritional therapy in children with cancer. Cancer Res 1977;37:2457-61.

4 Clayton PE, Morris-Jones PH, Shalet SM, Price DA. Growth in children treated for acute lymphoblastic leukaemia. Lancet 1988; ;:460-2.

5 Kien CL, Camitta BM. Close association of accelerated rates of whole body protein turnover (synthesis and breakdown) and energy expenditure in children with newly diagnosed acute lymphocytic leukemia. Foumal of Parenteral and Enteral Nutrition 1987;11:129-34.

6 Stallings VA, Vaisman N, Chan HSL, Weitzman SS, Hahn E, Pencharz PB. Energy metabolism in children with newly diagnosed acute lymphoblastic leukemia. Pediatr Res 1989; 26:154-7.

7 Merritt RJ, Ashley JM, Siegel SE, Sinatra FR, Thomas DW, Hays DM. Calorie and protein requirements of pediatric patients with acute nonlymphoblastic leukaemia. Foumal of patients with acute nonlymphoblastic leukaem
Parenteral and Enteral Nutrition 1981;5:20-3.

$8 \mathrm{Marr} \mathrm{JW}$. Individual dietary surveys: purposes of methods. World Rev Nutr Diet 1971;13:105-64.

9 Paul AA, Southgate DAT. McCance and Widdowson's the composition of foods. London: HMSO, 1978.

10 Tan SP, Wenlock, Buss DH. Second supplement to McCance and Widdowson's the composition of foods: immigrant foods. London: HMSO, 1985.

11 Holland B, Unwin ID, Buss DH. Third supplement to McCance and Widdowson's the composition of foods: cereal and cereal products. Nottingham: The Royal Society of Chemistry and The Ministry of Agriculture, Fisheries and Food, 1988.

12 Holland B, Unwin ID, Buss DH. Fourth supplement to McCance and Widdowson's the composition of foods: milk products and eggs. Cambridge: The Royal Society of Chemistry and The Ministry of Agriculture, Fisheries and Food, 1989.

13 Department of Health and Social Security. Recommended daily amounts of food energy and nutrients for groups of people daily amounts of food energy and nutrients for groups of people
in the United Kingdom. Report on health and social subjects No 15. London: HMSO, 1979 .

14 Dubois EF. Basal metabolism in health and disease. Philadelphia: Lea and Febiger, 1924.

15 Jequier E. Measurement of energy expenditure in clinical nutritional assessment. Fournal of Parenteral and Enteral Nutrition 1987;115:865-95.

16 Schofield WN. Predicting basal metabolic rate. New standards and review of previous work. Human Nutrition: Clinical Nutrition 1985;39C(suppl 1):5-41.

17 Tanner JM, Whitehouse RH. Growth and development record. Ware: Castlemead Publications, 1983.

18 Brook CGD. Determination of body composition of children from skinfold measurements. Arch Dis Child 1971;46: $182-4$.

19 Durnin JGVA, Rahaman MM. The assessment of the amount of fat in the human body from measurements of skinfold thickness. Brf Nutr 1967;21:681.

20 Siri WE. The gross composition of the body. Advances in biological medicine and physics. Vol 4. New York: Academic Press, 1956:239-80.

21 Jackson AA, Golden MHN. Severe malnutrition. Wetherall DJ, Ledingham JGG, Warrell DA, eds. Oxford textbook of medicine. 2nd Ed. Vol 1. 1987:8.12-28.

22 Waterlow JC, Buzina R, Keller W, Nichaman MZ, Tanner $J M$. The presentation and use of height and weight data for comparing the nutritional status of groups of children under the age of 10 years. Bull World Health Organ 1977;55:489-98.

23 van Eys J. The pathophysiology of undernutrition in the child with cancer. Cancer 1986;58:1874-80.

24 Shalet SM, Beardwell CG, Morris Jones PH, Pearson D. Growth hormone deficiency after treatment of acute leukaemia in children. Arch Dis Child 1976;51:489-93.

25 Swift PGF, Kearney PJ, Dalton RG, Bullimore JA, Mott MG, Savage DCL. Growth and hormonal status of children treated for acute lymphoblastic leukaemia. Arch Dis Child 1978;53:890-4.

26 Kirk JA, Stevens MM, Menser MA, et al. Growth failure and growth-hormone deficiency after treatment for acute growth-hormone deficiency after treatment
lymphoblastic leukaemia. Lancet $1987 ; \mathrm{i}: 190-3$.

27 James WPT, Schofield EC. Human energy requirements. Oxford: Oxford Medical Publications, 1990.

28 Bingham SA. The dietary assessment of individuals; methods, accuracy, new techniques and recommendations. Nutrition accuracy, new techniques and recommendations.

29 Livingstone MBE. Accuracy of weighed dietary records in studies of diet and health. $B M \mathcal{F}$ 1990;300:708-12. 